\title{
Transisi Fasa Elektrolemah
}

\author{
Bintoro Anang Subagyo* dan Agus Purwanto ${ }^{\dagger}$ \\ Laboratorium Fisika Teori dan Filsafat Alam (LaFTiFA), \\ Jurusan Fisika, FMIPA, Institut Teknologi Sepuluh Nopember \\ Kampus ITS Sukolilo, Surabaya 60111
}

\begin{abstract}
Intisari
Potensial efektif elektrolemah dirumuskan ulang untuk sektor energi tinggi. Analisis terhadap potensial efektif ini memberikan transisi fasa orde pertama pada skala di atas energi perusakan simetri spontan sekitar 100 $\mathrm{eV}$.

KATA KUNCI: osilasi neutrino, matrik bauran dan model seesaw
\end{abstract}

\section{PENDAHULUAN}

Fisika partikel elementer telah mengalami kemajuan dan sukses yang luar biasa. Saat ini semua interaksi antar partikel elementer dapat digambarkan dalam satu model atau teori yang disebut Model Standar. Teori ini menggabungkan teori unifikasi Glashow-Salam-Weinberg [1] bagi interaksi lemah dan elektromagnetik dan kromodinamika kuantum. Model ini telah teruji oleh eksperimen-eksperimen dengan ketelitian yang mengesankan.

Teori interaksi elektrolemah yang berbasis pada grup tera (gauge) $\mathrm{SU}(2) \mathrm{xU}(1)$ yang rusak secara spontan menggambarkan interaksi antara fermion fundamental (kuark dan lepton) dan boson tera vektor (W,Z dan gamma). Di sisi yang lain, kromodinamika kuantum yang bertumpu pada grup SU(3) menggambarkan interaksi kuark-gluaon secara kuat. Model standar merupakan salah satu pencapaian paling sukses di dalam fisika modern. Ia memberi kerangka kerja teoritis anggun yang dapat mendiskripsikan hasil-hasil eksperimen di dalam fisika partikel dengan presisi tinggi.

Salah satu konsep paling menarik sekaligus paling penting di dalam teori fisika partikel modern adalah perusakan simetri spontan (spontaneous symmetry breaking, SSB). Sebelum SSB semua massa partikel sama atau degenerasi, jelas tidak sesuai dengan kenyataan di alam. Mekanisme alamiah membangkikan massa tanpa harus merusak simetri sistem keseluruhan kecuali keadaan vakumnya dikenal sebagai SSB. Teori elektrolemah mengalami perusakan simetri spontan pada skala energi sekitar $100 \mathrm{GeV}$. Skala ini setara atau bersamaan dengan rentang waktu $10^{-11}$ " detik setelah ledakan besar (The Big Bang) ketika temperatur rata-rata alam semesta masih cukup tinggi yaitu $10^{15} \mathrm{~K}$.

Karena itu, menjadi relevan untuk memahami sifat dan perilaku interaksi elektrolemah pada wilayah dengan temperatur tinggi ini. Selanjutnya, teori medan temperatur hingga juga menjadi relevan diterapkan bagi teori interaksi lemah.

Jagad raya dalam skala besar diketahui hampir seluruhnya

\footnotetext{
*E-MAIL: b\_anang@physics.its.ac.id

${ }^{\dagger}$ E-MAIL: purwanto@physics.its.ac.id
}

terdiri dari materi tanpa antimateri dalam jumlah yang berarti. Kenyataan ini dikenal sebagai asimetri baryon dari jagad raya dan menjadi persoalan kosmologi yang sangat menarik untuk dijawab oleh fisika partikel [2].

Model kosmologi klasik tentang jagad raya atau alam semesta berkembang memberikan kerangka kerja yang ampuh bagi fisika partikel untu dapat diuji prediksinya tentang kelahiran materi. Ekspansi alam semesta dapat dipandang sebagai akselerator partikel yang sangat besar yang meskipun bekerja sekian milyar tahun lalu tetapi dapat untuk menguji keabsahan teori-teori yang terkait dengan partikel elementer.

Jagad raya bermula dari keadaan simetrik baryon tetapi interaksi partikel menghasilkan asimetri baryon. Pada tahun 1967 Sakharov [3] mengemukakan tiga syarat bagi terjadinya asimetri materi-antimateri ini. Syarat-syarat tersebut adalah (a) penyimpangan bilangan baryon, (b) penyimpangan $\mathrm{C}$ dan $\mathrm{CP}$ dan (c) jagad raya harus berada dalam nonkesetimbangan termal. Ketika gagasan ini dikemukakan jelas merupakan merupakan gagasan aneh karena tidak ada satu teori pun yang memenuhi persyatan-persyaratan tersebut. Baru di awal tahun 1970an syarat Sakharov ini dipenuhi oleh teori kemanunggalan agung berbasis grup simetri $\mathrm{SU}(5)$.

Model standar elektrolemah diketahui memenuhi dua persyaratan pertama. Di dalam model standar, struktur non-trivial vakum tera $\mathrm{SU}(2)$ dan proses anomali menyebabkan jumlah baryon tidak kekal. Di sisi lain simetri CP disimpangkan oleh fasa relatif antara interaksi tera elektrolemah dan interaksi Higgs bagi quark yang secara eksplisit terkandung di dalam matriks bauran Cabibbo-Kobayashi-Maskawa (CKM)[4].

Pertanyaannya apakah model standar elektrolemah juga memungkinkan nonkesetimbangan termal. Pertanyaan ini membuat penyelidikan di sekitar perusakan simetri elektrolemah menjadi sangat relevan khususnya perlakuan teori di dalam kerangka temperatur taknol.

Karena kehadiran simpangan bilangan baryon berlangsung pada energi tinggi model standar diharapkan mampu membangkitkan bilangan baryon pada skala elektrolemah atau di atasnya. Pemahaman kuantitatif tentang transisi fasa elektrolemah akan menjadi prasyarat dasar bagi diskusi model baryogenesis pada skala elektrolemah.

Di Bagian II makalah ini ditampilkan kembali kandungan medan dari model standar elektrolemah dan perusakan 
simetri spontan sebagai mekanisme pembangkitan massa bagi semua medan. Konstruksi potensial efektif yakni potensial dengan kontribusi loop, di makalah ini dibatasi loop-tunggal, pada temperatur nol maupun temperatur hingga dilakukan di Bagian III. Evolusi potensial efektif terhadap temperatur diberikan di Bagian IV. Akhirnya, diskusi dan kesimpulan di Bagian V.

\section{MODEL STANDAR ELEKTROLEMAH}

\section{A. Teori Tera Elektrolemah}

Model yang memadukan interaksi lemah dan elektromagnetik dikenal sebagai model standar elektrolemah dirumuskan secara terpisah oleh S.Glashow, A. Salam dan S.Weinberg. Di dalam model ini terkandung tiga medan yaitu medan materi quark $q$ dan lepton $\ell$, medan pembawa interaksi boson tera (gauge boson) $A_{\mu}$ dan $B_{\mu}$, dan medan Higgs $\Phi$ pembangkit massa bagi medan materi maupun boson tera.

Model standar elektrolemah berbasis grup non-abelian $S U(2)_{L} \times U(1)_{Y}$ dan mempunyai empat generator. Perantara interaksi lemah adalah tiga boson vektor $A_{\mu}^{a}, a=1,2,3$ yang ditampung dalam representasi ajoin dari grup $S U(2)$ yang ditandai oleh $S U(2)_{L}$ dengan generator $T_{a}=\sigma_{a}$ dan $\sigma_{a}$ adalah matriks Pauli, dan $T_{a}$ dikenal sebagai generator isospin lemah. Indeks $L$ menandai bahwa $A_{\mu}^{a}$ terkopel dalam penyimpangan paritas dengan bagian kiri medan materi lepton yang bertransformasi sebagai doblet terhadap $S U(2)_{L}$.

Interaksi elektromagnetik diperantarai oleh satu boson tera $B_{\mu}$ dalam grup $U(1)_{Y}$. Generator grup $U(1)_{Y}$ adalah $Y / 2$ dengan $Y$ adalah hipermuatan lemah yang didefinisikan menurut hubungan Gell-Mann-Nishijima

$$
Q=T_{3}+Y / 2
$$

dan $T_{3}$ adalah komponen ketiga isospin lemah.

Rapat Lagrangian bagi fermion diberikan oleh

$$
\begin{aligned}
\mathcal{L}_{f}= & \sum_{f_{L}} \bar{f}_{L} \gamma^{\mu}\left(i \partial_{\mu}-g \frac{\tau_{a}}{2} A_{\mu}^{a}-g^{\prime} \frac{Y}{2} B_{\mu}\right) f_{L} \\
+ & \sum_{f_{R}} \bar{f}_{R} \gamma^{\mu}\left(i \partial_{\mu}-g^{\prime} \frac{Y}{2} B_{\mu}\right) f_{R}
\end{aligned}
$$

dengan fermion doublet $f_{L}$

$$
q_{u L}=\left(\begin{array}{c}
u \\
d
\end{array}\right)_{L}, q_{c L}=\left(\begin{array}{c}
c \\
s
\end{array}\right)_{L}, q_{t L}=\left(\begin{array}{c}
t \\
b
\end{array}\right)_{L},
$$

untuk quark dan

$$
e_{L}=\left(\begin{array}{c}
\nu_{e} \\
e
\end{array}\right)_{L}, \mu_{L}=\left(\begin{array}{c}
\nu_{\mu} \\
\mu
\end{array}\right)_{L}, \tau_{L}=\left(\begin{array}{c}
\nu_{\tau} \\
\tau
\end{array}\right)_{L},
$$

untuk lepton; sedangkan fermion singlet $f_{R}$

$$
u_{R}, c_{R}, t_{R}, d_{R}, s_{R}, b_{R}
$$

untuk quark

$$
e_{R}, \mu_{R}, \tau_{R}
$$

untuk lepton.

Rapat Lagrangian bagi suku kinetik dua medan tera

$$
\mathcal{L}_{g}=-\frac{1}{4} F_{\mu \nu}^{a} F^{a \mu \nu}-\frac{1}{4} B_{\mu \nu} B^{\mu \nu},
$$

dengan tensor kekuatan medan bagi medan tera $S U(2)_{L}$

$$
F_{\mu \nu}^{a}=\partial_{\mu} A_{\nu}^{a}-\partial_{\nu} A_{\mu}^{a}+g \epsilon^{a b c} A_{\mu}^{b} A_{\nu}^{c},
$$

dan tensor kekuatan medan bagi medan tera $U(1)_{Y}$

$$
B_{\mu \nu}=\partial_{\mu} B_{\nu}-\partial_{\nu} B_{\mu}
$$

Dari Lagrangian (2) dan (7) tampak bahwa materi dan boson tera tidak bermassa. Penambahan suku $\frac{1}{2} m_{B}^{2} B_{\mu} B^{\mu}$ dan serupa bagi $A_{\mu}^{a}$ jelas tidak invarian tera. Suku massa fermion harus dalam bentuk

$$
-m \bar{f} f=-m\left(\bar{f}_{R} f_{L}+\bar{f}_{L} f_{R}\right) .
$$

Suku ini jelas merusak invariansi chiral tera karena $f_{L}$ adalah anggota doublet $S U(2)_{L}$ sedangkan $f_{R}$ singlet. Karena secara eksperimen baik fermion maupun boson tera bermassa maka massa mereka harus dibangkitkan tanpa harus merusak invariansi simetri terkait.

\section{B. Perusakan Simetri Spontan}

Untuk membangkitkan massa bagi materi dan boson perantara interaksi diperkenalkan satu medan skalar kompleks Doublet $S U(2)$ dengan hipermuatan $Y=1[5]$,

$$
\Phi=\left(\begin{array}{c}
\phi^{+} \\
\phi^{0}
\end{array}\right)
$$

Lagrangian ivarian terhadap transformasi simetri

$$
\mathcal{L}_{\phi}=\left(D^{\mu} \Phi\right)^{\dagger}\left(D_{\mu} \Phi\right)-V(\Phi)
$$

dengan turunan kovarian

$$
D_{\mu}=\partial_{\mu}-i g \frac{\tau_{a}}{2} A_{\mu}^{a}-i g^{\prime} \frac{Y}{2} B_{\mu}
$$

dan potensial invarian tera

$$
V(\Phi)=-\mu^{2} \Phi^{\dagger} \Phi+\lambda\left(\Phi^{\dagger} \Phi\right)^{2}
$$

Potensial ini mempunyai minimum pada lingkaran $\Phi^{\dagger} \Phi=$ $\mu^{2} / 2 \lambda$ yang berarti mempunyai keadaan dasar degenerasi. Sekali kita pilih satu keadaan, misalkan

$$
\langle\Phi\rangle_{0}=\frac{1}{\sqrt{2}}\left(\begin{array}{l}
0 \\
\sigma
\end{array}\right)
$$

keadaan dasar tidak lagi merupakan simetri dari Lagrangian. Invariansi Lagrangian dipertahankan sedangkan keadaan 
vakum tidak, mekanisme ini dikenal sebagai perusakan simetri spontan (spontaneous symmetry breaking).

Setelah perusakan simetri spontan Lagrangian suku kinetik medan skalar $\left(D^{\mu} \Phi\right)^{\dagger}\left(D_{\mu} \Phi\right)$ membangkitkan massa boson vektor. Dua boson vektor yang didefinisikan melalui kombinasi linier

$$
W_{\mu}^{ \pm}=\frac{1}{\sqrt{2}}\left(A_{\mu}^{1} \pm i A_{\mu}^{2}\right)
$$

mempunyai massa klasik

$$
m_{W}=\frac{1}{2} g \sigma
$$

dengan $\sigma$ adalah nilai harap vakum dari medan Higgs. Sedangkan medan boson vektor netral yang muncul dalam kombinasi linier

$$
Z_{\mu}=\frac{g^{\prime} B_{\mu}-g A_{\mu}^{3}}{\sqrt{g^{2}+g^{\prime 2}}}
$$

mempunyai massa klasik

$$
m_{Z}=\frac{\sigma}{2 \sqrt{g^{2}+g^{\prime 2}}}
$$

Foton tetap tidak bermassa $m_{A}=0$ dan muncul sebagai kombinasi linier

$$
Z_{\mu}=\frac{g^{\prime} B_{\mu}+g A_{\mu}^{3}}{\sqrt{g^{2}+g^{\prime 2}}}
$$

Massa fermion dapat dibangkitnya dengan cara serupa dengan memperkenalkan Lagrangian interaksi Yukawa antara fermion dan medan skalar Higgs.

$$
\mathcal{L}_{Y}=Y_{\ell} \bar{\ell}_{L} \Phi \ell_{R}+Y_{d} \bar{q}_{R} \Phi q_{R}+Y_{u} \bar{q}_{R} \tilde{\Phi} q_{R}
$$

Doublet Higgs baru $\tilde{\Phi}$ didefinisikan sebagai

$$
\tilde{\Phi}=-i \tau_{2} \Phi^{\dagger}=\left(\begin{array}{c}
-\phi^{0} \\
\phi^{-}
\end{array}\right)
$$

dan bertransformasi sama dengan $\Phi$ tetapi dengan hipermuatan $Y=-1$ diperkenalkan untuk membangkitkan massa quark komponen atas. Setelah perusakan simetri lepton bermuatan dan quark bermassa

$$
m_{f}=\frac{Y_{f} \sigma}{\sqrt{2}}
$$

\section{POTENSIAL EFEKTIF}

\section{A. Temperatur Nol}

Potensial (14) dikenal sebagai potensial klasik dari teori medan kuantum dan seperti telah dibahas di depan memainkan peran sangat penting dalam perusakan simetri spontan. Di dalam perusakan simetri spontan ini tidak dilibatkan kehadiran efek kuantum berupa loop yang biasa disebut koreksi radiatif. Padahal koreksi radiatif di dalam teori kuantum kadang-kadang merubah perilaku dari potensial klasik ini. Minimum dari potensial klasik mungkin tidak stabil terhadap koreksi radiatif. Simetri yang rusak spontan secara klasik mungkin akan dipulihkan dengan adanya koreksi radiatif atau sebaliknya simetri yang tidak rusak pada tingkat klasik mungkin menjadi rusak secara spontan akibat adanya efek kuantum.

Potensial efektif merupakan potensial sistem yang telah melibatkan koreksi kuantum. Secara sederhana potensial efektif dapat dinyatakan sebagai potensial klasik $V_{0}$ dan potensial dengan efek kuantum $V_{1}$ sebagai berikut

$$
V_{e f f}\left(\phi_{c}\right)=V_{0}\left(\phi_{c}\right)+V_{1}\left(\phi_{c}\right) .
$$

dengan $\phi_{c}$ sebagai medan klasik yang memberi minimum potensial polos (tree-level) tidak remeh, $\phi_{c}=\langle 0|\phi| 0\rangle \neq 0$.

Kita akan membatasi koreksi atau kontribusi loop-tunggal untuk semua medan dari teori yaitu skalar, fermion dan boson tera.

\section{Medan Skalar}

Lagrangian medan skalar riel interaksi diri berbentuk

$$
\mathcal{L}=\frac{1}{2} \partial^{\mu} \phi \partial_{\mu} \phi-V_{0}(\phi)
$$

dengan potensial polos

$$
V_{0}=\frac{1}{2} m^{2} \phi^{2}+\frac{\lambda}{4 !} \phi^{4}
$$

Koreksi loop-tunggal (one-loop) terhadap potensial polos dilakukan dengan menjumlahkan seluruh diagram 1PI dengan loop tunggal dan momentum eksternal nol seperti pada Gambar 1, yang mana setiap verteks memiliki dua kaki eksternal. Dari gambar tampak bahwa diagram ke- $n$ memiliki $n$ propa-
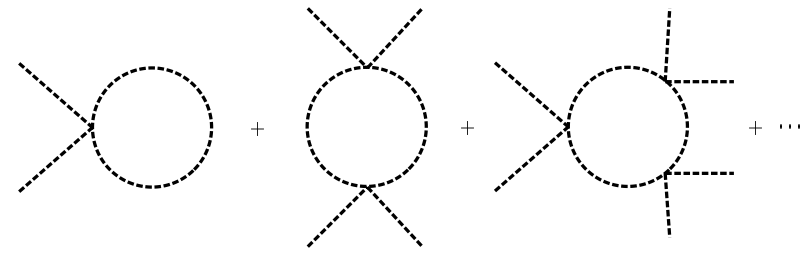

Gambar 1: Diagam1PI yang memberikan kontribusi pada potensial effektif loop-tunggal

gator, $n$ verteks, dan $2 n$ kaki eksternal. $n$ propagator memberikan kontribusi faktor $i^{n}\left(p^{2}-m^{2}+i \epsilon\right)^{-n}$. Garis eksternal menyumbangkan faktor $\phi_{c}^{2 n}$ dan setiap verteks faktor dari $-i \lambda / 2$, dimana muncul faktor $1 / 2$ dari kenyataan bahwa pertukaran 2 kaki eksternal pada setiap verteks tidak mengubah diagram. Terdapat faktor simetri global $1 / 2 n$ dimana faktor $1 / n$ berasal dari kesimetrian terhadap group rotasi $\mathbb{Z}$ dan $1 / 2$ dari simetri dari diagram ari proses refleksi. Terakhir, terdapat 
integrasi meliputi seluruh momentum loop dan faktor ekstra $i$ muncul dari definisi fungsional pembangkit.

Menggunakan aturan di atas potensial efektif oleh looptunggal dapat dihitung sebagai

$$
\begin{aligned}
V_{1 s}\left(\phi_{c}\right) & =i \sum_{n=1}^{\infty} \int \frac{d^{4} p}{(2 \pi)^{4}} \frac{1}{2 n}\left[\frac{\lambda \phi_{c}^{2} / 2}{p^{2}-m^{2}+i \epsilon}\right]^{n} \\
& =-\frac{i}{2} \int \frac{d^{4} p}{(2 \pi)^{4}} \log \left[1-\frac{\lambda \phi_{c}^{2} / 2}{p^{2}-m^{2}+i \epsilon}\right]
\end{aligned}
$$

Setelah dilakukan rotasi Wick persamaan (27) dapat diungkapkan sebagai

$$
V_{1 s}\left(\phi_{c}\right)=\frac{1}{2} \int \frac{d^{4} p_{E}}{(2 \pi)^{4}} \log \left[1+\frac{\lambda \phi_{c}^{2} / 2}{p_{E}^{2}+m^{2}}\right]
$$

Setelah menanggalkan indeks $E$, potensial efektif ini dapat dituliskan sebagai

$$
V_{1 s}\left(\phi_{c}\right)=\frac{1}{2} \int \frac{d^{4} p}{(2 \pi)^{4}} \log \left[p^{2}+m^{2}\left(\phi_{c}\right)\right]
$$

dengan

$$
m^{2}\left(\phi_{c}\right)=m^{2}+\frac{1}{2} \lambda \phi_{c}^{2}=\frac{d^{2} V_{0}\left(\phi_{c}\right)}{d \phi_{c}^{2}} .
$$

\section{Medan Fermion}

Medan fermion digambarkan oleh Lagrangian,

$$
\mathcal{L}=i \psi_{a} \gamma \cdot \partial \psi^{a}-\bar{\psi}_{a}\left(m_{f}\right)_{b}^{a} \psi^{b}
$$

dengan matriks massa $\left(m_{f}\right)_{b}^{a}\left(\phi_{c}^{i}\right)$ merupakan fungsi dari medan skalar $\phi_{c}^{i}:\left(m_{f}\right)_{b}^{a}=\Gamma_{b i}^{a} \phi_{c}^{i}$.

Kontribusi loop-tunggal secara diagramatik diberikan oleh Gambar 2. Diagram dengan jumlah verteks ganjil nol karena

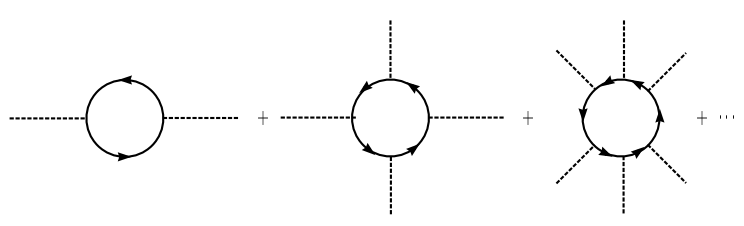

Gambar 2: Diagram 1PI kontribusi terhadap potensial efektif looptunggal

sifat matriks $\gamma$ yang nir-trace dan antikomut. Diagram dengan $2 n$ verteks memiliki $2 n$ propagator fermion. Evaluasi propagator menghasilkan faktor

$$
\operatorname{Tr}_{s}\left[i^{2 n}(\gamma \cdot p)^{2 n}\left(p^{2}+i \epsilon\right)^{-2 n}\right]
$$

dengan $\operatorname{Tr}_{s}$ indeks spinor. Verteks memberikan kontribusi

$$
\operatorname{Tr}\left[-i^{2 n} m_{f}\left(\phi_{c}\right)^{2 n}\right]
$$

dimana trace berjalan meliputi medan fermion yang berbeda. Faktor kombinasi $\frac{1}{2 n}$ dari sifat simetri siklis dan antisiklis diagram dan keseluruhannya -1 datang dari loop fermion. Akhirnya diperoleh faktor

$$
-\frac{1}{2 n} \frac{\operatorname{Tr}\left(m_{f}^{2 n}\right)}{p^{2 n}} \cdot \operatorname{Tr}_{s} \mathbf{1}
$$

Faktor $\operatorname{Tr}_{s} 1$ hanya untuk jumlah derajat kebebasan fermion, sama dengan 4 untuk fermion Dirac, dan 2 jika fermion Weyl. Sehingga $\operatorname{Tr}_{s} \mathbf{1}=2 \lambda$ dengan $\lambda=1$ untuk fermion Weyl dan $\lambda=2$ untuk fermion Dirac. Disamping itu telah kita kelompokkan suku-suku pasangan dalam perkalian matriks dan menggunakan $\tilde{p}^{2}=p^{2}$ dengan $\tilde{p}$ berlaku untuk $p \cdot \gamma$ maupun $p \cdot \sigma$ sesuai jenis fermionnya.

Kontribusi loop-tunggal terhadap potensial efektif dari medan fermion berbentuk

$$
\begin{aligned}
V_{1 f} & =-2 \lambda i \operatorname{Tr} \sum_{n=1}^{\infty} \int \frac{d^{4} p}{(2 \pi)^{4}} \frac{1}{2 n}\left[\frac{m_{f}^{2}}{p^{2}}\right]^{n} \\
& =\lambda i \operatorname{Tr} \int \frac{d^{4} p}{(2 \pi)^{4}} \log \left[1-\frac{m_{f}^{2}}{p^{2}}\right]
\end{aligned}
$$

Sebagaimana untuk medan skalar, setelah rotasi Wick ke ruang momentum Euclidean dan mengabaikan medan yang tak bersesuaian kita dapat mengungkapkan persamaan (32) sebagai

$$
V_{1 f}=-\lambda \operatorname{Tr} \int \frac{d^{4} p}{(2 \pi)^{4}} \log \left[p^{2}+m_{f}^{2}\left(\phi_{c}\right)\right]
$$

\section{Medan Boson}

Terakhir, kita bahas boson tera dengan Lagrangian

$$
\mathcal{L}=-\frac{1}{4} \operatorname{Tr}\left(F_{\mu \nu} F^{\mu \nu}\right)+\frac{1}{2} \operatorname{Tr}\left(D_{\mu} \phi_{a}\right)^{\dagger} D^{\mu} \phi^{a}+\cdots
$$

Dalam tera Landau, dimana tidak memerlukan kompensasi suku hantu, propagator boson tera bebas berbentuk

$$
\Pi_{\nu}^{\mu}=-\frac{i}{p^{2}+i \epsilon} \Delta_{\nu}^{\mu}
$$

dengan

$$
\Delta_{\nu}^{\mu}=g_{\nu}^{\mu}-\frac{p^{\mu} p_{\nu}}{p^{2}}
$$

memenuhi sifat $p_{\mu} \Delta^{\mu}{ }_{\nu}=0$ dan $\Delta^{n}=\Delta, n=1,2, \ldots$ Satu-satunya verteks yang berkontribusi pada loop-tunggal

$$
\mathcal{L}=\frac{1}{2}\left(m_{g b}\right)_{\alpha \beta}^{2} A_{\mu}^{\alpha} A^{\mu \beta}+\cdots
$$

dengan

$$
\left(m_{g b}\right)_{\alpha \beta}^{2}\left(\phi_{c}\right)=g_{\alpha} g_{\beta} \operatorname{Tr}\left[\left(T_{\alpha \ell}^{i} \phi_{i}\right)^{\dagger} T_{\beta j}^{\ell} \phi^{j}\right]
$$



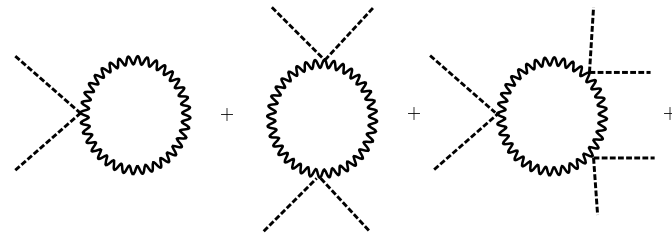

Gambar 3: Gambar 1PI yang memberikan kontribusi pada potensial loop-tunggal

Dalam hal ini diagram yang berkontribusi pada potensial efektif loop-tunggal dijelaskan pada Gambar III A 3. Masukkan faktor kombinasi pada perhitungan , diagram dengan $n$ propagator and $n$ verteks menyisakan sebuah faktor

$$
\frac{1}{2 n} \frac{\operatorname{Tr}\left(\left(m_{g b}\right)^{2}\right)^{n}}{p^{2 n}} \operatorname{Tr}(\Delta)
$$

dengan $\operatorname{Tr}(\Delta)=3$ dimana jumlah derajat kebebasan dari boson tera masif. Kumpulkan semua faktor bersama, dan lakukan rotasi Wick pada ruang momentum euclidean, kita dapat memasukkan potensial efektif dari boson tera sebagai,

$$
V_{1 b}=\frac{3}{2} \operatorname{Tr} \int \frac{d^{4} p}{(2 \pi)^{4}} \log \left[p^{2}+\left(m_{g b}\right)^{2}\left(\phi_{c}\right)\right]
$$

\section{Renormalisasi}

Secara matematis loop senantiasa memberi nilai tak berhingga atau divergensi dan untuk mengatasi penyakit matematis ini di dalam teori medan kuantum diperkenalkan konsep renormalisasi bagi teori. Divergensi diregularisasi dan kontribusi divergen diserap ke dalam suku pasangan (counterterm)

$$
V_{1}^{\text {c.t. }}=\delta \Omega+\frac{\delta m^{2}}{2} \phi_{c}^{2}+\frac{\delta \lambda}{4} \phi_{c}^{4}
$$

untuk keperluan mendatang telah diperkenalkan suku pasangan $\delta \Omega$ bagi energi vakum atau konstanta kosmologi.

Ada beberapa cara regulasi, di makalah ini akan digunakan renormalisasi cut-off. Sebagai ilustrasi kita ambil medan skalar riel takbermassa dengan Lagrangian

$$
\mathcal{L}=\frac{1}{2}(1+\delta Z)\left(\partial_{\mu} \phi\right)^{2}-\frac{1}{2} \delta m^{2} \phi^{2}-\frac{\lambda+\delta \lambda}{4 !} \phi^{4}
$$

dengan $\delta Z, \delta m^{2}$ dan $\delta \lambda$ fungsi gelombang, massa dan konstanta kopling suku counterterm renormalisasi.

Definisi konvensional dari massa terenormalisasi medan skalar merupakan invers negatif dari propagator pada momentum nol, yaitu

$$
m_{R}^{2}=-\Gamma^{(2)}(p=0)=\left.\frac{d^{2} V}{d \phi_{c}^{2}}\right|_{\phi_{c}=0} .
$$

Sedangkan kopling terenormalisasi didefinisikan sebagai fungsi empat-titik pada momentum eksternal nol,

$$
\lambda_{R}=-\Gamma^{(4)}(p=0)=\left.\frac{d^{4} V}{d \phi_{c}^{4}}\right|_{\phi_{c}=0}
$$

dan kondisi standar untuk medan renormalisasi

$$
Z(0)=1
$$

Sekarang kita hitung potensial efektif (29) dengan batas atas integral $p^{2}=\Lambda^{2}$. Menggunakan integral seluruh variabel kecuali radius $\rho$ memberikan

$$
\int d^{n} p f(\rho)=\frac{\pi^{n / 2}}{\Gamma\left(\frac{n}{2}\right)} \int f(\rho) \rho^{n / 2-1} d \rho
$$

dengan $\rho=|p|^{2}$ dan persamaan (29) dapat dinyatakan sebagai

$$
V_{1 s}\left(\phi_{c}\right)=\frac{1}{32 \pi^{2}} \int_{0}^{\Lambda^{2}} \rho \log \left[\rho+m^{2}\left(\phi_{c}\right)\right] d \rho .
$$

Menggunakan integral taktentu berikut

$\int x \log (a+x) d x=\frac{1}{2}\left(x^{2}-a^{2}\right) \log (a+x)-\frac{1}{2}\left(\frac{x^{2}}{2}-a x\right)$ dan mengabaikan suku yang takbergantung medan didapatkan,

$V_{1}\left(\phi_{c}\right)=\frac{1}{32 \pi^{2}} m^{2}\left(\phi_{c}\right) \Lambda^{2}+\frac{1}{64 \pi^{2}} m^{4}\left(\phi_{c}\right)\left[\log \frac{m^{2}\left(\phi_{c}\right)}{\Lambda^{2}}-\frac{1}{2}\right]$

Sekarang gunakan (46) potensial loop-tunggal (41) dapat dituliskan sebagai,

$$
\begin{aligned}
V= & \frac{1}{2} \delta m^{2} \phi_{c}^{2}+\frac{\lambda+\delta \lambda}{4 !} \phi_{c}^{4}+\frac{\lambda \phi_{c}^{2}}{64 \pi^{2}} \Lambda^{2} \\
& +\frac{\lambda^{2} \phi_{c}^{4}}{256 \pi^{2}}\left(\log \frac{\lambda \phi_{c}^{2}}{2 \Lambda^{2}}-\frac{1}{2}\right)
\end{aligned}
$$

Kita akan memasukkan satu kondisi renormalisation (42), (43) and (44). Untuk massa terenormalisasi kita dapat memasukkannya agar hilang, yaitu

$$
\left.\frac{d^{2} V}{d \phi_{c}^{2}}\right|_{\phi_{c}=0}=0
$$

Untuk merenormalisasi kopling $\lambda$, tidak dapat digunakan persamaan (43) pada sebuah nilai dari medan sama dengan nol melainkan menggunakan,

$$
\lambda=\left.\frac{d^{4} V}{d \phi_{c}^{4}}\right|_{\phi_{c}=\mu}
$$

dimana $\mu$ skala massa. Perbedaan pemilihan skala membawa pada difinisi yang berbeda dari konstanta kopling. Secara prinsip hal tersebut sama saja dengan $\mu$ lainnya.

Subtitusi kondisi (48) dan (49) ke (47) maka suku pasangan dapat dituliskan sebagai,

$$
\delta m^{2}=-\frac{\lambda}{32 \pi^{2}} \Lambda^{2}
$$

dan

$$
\delta \lambda=-\frac{11 \lambda^{2}}{32 \pi^{2}}-\frac{3 \lambda^{2}}{32 \pi^{2}} \log \frac{\lambda \mu^{2}}{2 \Lambda^{2}}
$$


Gunakan (50) dan (51) dalam (47) maka potensial efektif loop-tunggal terenormalisasi diberikan oleh ungkapan,

$$
V_{\text {eff }}=\frac{\lambda}{4 !} \phi_{c}^{4}+\frac{\lambda^{2} \phi_{c}^{4}}{256 \pi^{2}} \log \left(\frac{\phi_{c}^{2}}{\mu^{2}}-\frac{25}{6}\right)
$$

Skema renormalisasi yang sama diterapkan bagi medan fermion dan boson tera. Ada catatan yang perlu diberikan untuk renormalisasi boson tera yaitu regularisasi momentum cut-off merusak invariansi tera sehingga perlu dilakukan dengan cara lain dan dalam kasus ini regulasi dimensional lebih sesuai.

\section{B. Temperatur Hingga}

Perumusan potensial efektif terdahulu dilakukan tanpa mempertimbangkan temperatur padahal di masa sangat awal alam semesta temperatur sedemikian tinggi dan tidak dapat diabaikan begitu saja. Dalam kasus seperti ini rumusan teori medan kuantum temperatur hingga menjadi relevan. Ada tiga perumusan bagi teori medan temperatur hingga yaitu perumusan waktu imajiner, waktu riel dan dinamika medan termo yang masing-masing digunakan sesuai kondisi fisis tertentu[6].

Potensial effektif untuk temperatur hingga diberikan seperti (24) dengan menambahkan temperatur

$$
V_{\text {eff }}\left(\phi_{c}, T\right)=V_{0}\left(\phi_{c}\right)+V_{1}\left(\phi_{c}, T\right)
$$

dengan $V_{0}\left(\phi_{c}\right)$ adalah potensial polos tanpa temperatur.

\section{Medan Skalar}

Pada temperatur hingga, menggunakan formalisme waktu imajiner, integral terhadap momentum skalar $p_{o}$ di dalam potensial efektif (29) digantikan oleh penjumlahan terhadap frekwensi Matsubara bosonik $\omega_{n}=2 n \pi T$ sehingga potensial menjadi efektif menjadi,

$$
V_{1 s}\left(\phi_{c}, T\right)=\frac{T}{2} \sum_{n=-\infty}^{\infty} \int \frac{d^{3} p}{(2 \pi)^{3}} \log \left(\omega_{n}^{2}+\omega^{2}\right)
$$

dengan $\omega=\sqrt{\vec{p}^{2}+m^{2}\left(\phi_{c}\right)}$.

Evaluasi persamaan (54) dilakukan dengan menjumlahkan terhadap moda frekwensi Matsubara dengan mendefinisikan

$$
v(\omega)=\sum_{n=-\infty}^{\infty} \log \left(\omega_{n}^{2}+\omega^{2}\right)
$$

Setelah menerapkan trik standar seperti diberikan di Appendiks diperoleh

$$
v(\omega)=\frac{2}{T}\left[\frac{w}{2}+T \log \left(1-e^{-\omega / T}\right)\right]+\text { tetapan }
$$

Substitusikan bentuk (56) ke dalam (53) didapatkan,

$$
V_{1 s}\left(\phi_{c}, T\right)=\int \frac{d^{3} p}{(2 \pi)^{3}}\left[\frac{\omega}{2}+T \log \left(1-e^{-\omega / T}\right)\right]
$$

Suku integral pertama pada (57) tidak lain adalah potensial efektif loop-tunggal temperatur nol

$$
\int \frac{d^{3} p}{(2 \pi)^{3}} \omega=\int \frac{d^{4} p}{(2 \pi)^{4}} \log \left[p^{2}+m^{2}\left(\phi_{c}\right)\right]
$$

Suku kedua persamaan (57) merupakan suku yang bergantung temperatur dan dapat dituliskan sebagai,

$$
T \int \frac{d^{3} p}{(2 \pi)^{3}} \log \left(1-e^{-\omega / T}\right)=\frac{T^{4}}{2 \pi^{2}} J_{B}\left[m^{2}\left(\phi_{c}\right) / T^{2}\right]
$$

dengan fungsi thermal bosonic $J_{B}$ didefinisikan oleh,

$$
J_{B}\left[m^{2} / T^{2}\right]=\int_{0}^{\infty} d x x^{2} \log \left[1-e^{-\sqrt{x^{2}+m^{2} / T^{2}}}\right]
$$

Integral (60) dan potensial efektif termal bosonik memuat ekspansi temperatur tinggi yang diberikan oleh

$$
\begin{gathered}
J_{B}\left(m^{2} / T^{2}\right)=-\frac{\pi^{4}}{45}+\frac{\pi^{2}}{12} \frac{m^{2}}{T^{2}}-\frac{\pi}{6}\left(\frac{m^{2}}{T^{2}}\right)^{3 / 2} \\
-\frac{1}{32} \frac{m^{4}}{T^{4}} \log \frac{m^{2}}{a_{b} T^{2}} \\
-2 \pi^{7 / 2} \sum_{\ell=1}^{\infty}(-1)^{\ell} \frac{\zeta(2 \ell+1)}{(\ell+1) !} \Gamma\left(\ell+\frac{1}{2}\right)\left(\frac{m^{2}}{4 \pi^{2} T^{2}}\right)^{\ell+2}
\end{gathered}
$$

dengan $a_{b}=16 \pi^{2} \exp \left(3 / 2-2 \gamma_{E}\right)\left(\log a_{b}=5.4076\right)$ dan $\zeta$ merupakan fungsi Riemann $\zeta$.

\section{Medan Fermion}

Evaluasi serupa dapat diterapkan untuk kasus medan fermion dalam temperatur hingga. Untuk medan fermion, frekwensi Matsubara berbeda dari kasus boson yaitu $\omega_{n}=$ $(2 n+1) \pi T$ dan potensial efektif menjadi

$$
V_{1 f}\left(\phi_{c}, T\right)=-\lambda T \sum_{n=-\infty}^{\infty} \int \frac{d^{3} p}{(2 \pi)^{3}} \log \left(\omega_{n}^{2}+\omega^{2}\right)
$$

dengan $\omega=\sqrt{\vec{p}^{2}+m_{f}^{2}}$. Menggunakan trik serupa dengan kasus skalar atau boson, lengkapnya lihat di Appendiks, didapatkan

$$
V_{1 f}\left(\phi_{c}, T\right)=-2 \lambda \int \frac{d^{3} p}{(2 \pi)^{3}}\left[\frac{\omega}{2}+T \log \left(1+e^{-\omega / T}\right)\right]
$$

yang berbeda tanda plus minus dari kasus sama untuk skalar dan boson.

Integral pertama in (63) membawa pada potensial efektif loop-tunggal pada temperatur nol. Integral kedua, yang mengandung suku dapat dituliskan sebagai

$$
-2 \lambda T \int \frac{d^{3} p}{(2 \pi)^{3}} \log \left(1+e^{-\omega / T}\right)=-\frac{\lambda T^{4}}{\pi^{2}} J_{F}\left[m_{f}^{2}\left(\phi_{c}\right) / T^{2}\right]
$$


dengan fungsi thermal fermionic $J_{F}$ didefinisikan sebagai,

$$
J_{F}\left[m^{2} / T^{2}\right]=\int_{0}^{\infty} d x x^{2} \log \left[1+e^{-\sqrt{x^{2}+m^{2} / T^{2}}}\right]
$$

Sebagaimana pada medan skalar, integral (65) dan oleh karena itu potensial efektif termal fermionik memuat ekspansi temperatur tinggi diberikan oleh

$$
J_{F}\left(m^{2} / T^{2}\right)=\frac{7 \pi^{4}}{360}-\frac{\pi^{2}}{24} \frac{m^{2}}{T^{2}}-\frac{1}{32} \frac{m^{4}}{T^{4}} \log \frac{m^{2}}{a_{f} T^{2}}-\frac{\pi^{7 / 2}}{4} \sum_{\ell=1}^{\infty}(-1)^{\ell} \frac{\zeta(2 \ell+1)}{(\ell+1) !}\left(1-2^{-2 \ell-1}\right) \Gamma\left(\ell+\frac{1}{2}\right)\left(\frac{m^{2}}{\pi^{2} T^{2}}\right)^{\ell+2}(66)
$$

dengan $a_{f}=\pi^{2} \exp \left(3 / 2-2 \gamma_{E}\right)\left(\log a_{f}=2.6351\right) \operatorname{dan} \zeta$ merupakan fungsi Riemann $\zeta$.

\section{Medan Boson}

Terakhir untuk boson potensial efektif termal boson tera pada lagrangian (34) dihitung dengan cara yang sama dengan medan skalar ataupun fermionik. Dengan menghitung diagram kecebong menggunakan massa tergeser untuk boson tera. Pada tera Landau, propagator boson tera,

$$
\Pi_{\nu}^{\mu}(p)^{(\alpha \beta)}=\Delta_{\nu}^{\mu} G^{(\alpha \beta)}(p)
$$

dengan $\Delta$ adalah projector yang didefinisikan dalam (??) dengan trace sama dengan 3 . Olehkarena itu ungkapan akhir potensial efektif thermal dihitung sebagai,

$$
\begin{aligned}
V_{1}\left(\phi_{c}, T\right)= & \frac{3}{2} \int \frac{d^{4} p}{(2 \pi)^{4}} \log \left[p^{2}+m_{g b}^{2}\left(\phi_{c}\right)\right] \\
& +\frac{3 T^{4}}{2 \pi^{2}} J_{B}\left[m_{g b}^{2}\left(\phi_{c}\right) / T^{2}\right]
\end{aligned}
$$

dengan fungsi bosonik thermal $J_{B}$ pada (60).

\section{TRANSISI FASA}

\section{A. Potensial Efektif Model Standar}

\section{Temperatur Nol}

Medan skalar dari model standar digambarkan oleh doblet $S U(2)$

$$
\Phi=\left(\begin{array}{c}
\chi_{1}+i \chi_{2} \\
\frac{\phi_{c}+h+i \chi_{3}}{\sqrt{2}}
\end{array}\right)
$$

dengan $\phi_{c}$ merupakan medan skalar riel latar belakang, $h$ medan Higgs dan $\chi_{a},(a=1,2,3)$ merupakan tiga medan boson Goldston. Potensial polos dalam medan latar belakang

$$
V_{0}\left(\phi_{c}\right)=-\frac{m^{2}}{2} \phi_{c}^{2}+\frac{\lambda}{4} \phi_{c}^{4}
$$

dengan nilai $\lambda$ dan $m^{2}$ positif, dan potensial polos minimum berkaitan dengan harga ekspektasi vakum dari medan $\phi_{c}$

$$
v^{2}=\frac{m^{2}}{\lambda}
$$

Massa medan skalar

$$
\begin{aligned}
& m_{h}^{2}\left(\phi_{c}\right)=3 \lambda \phi_{c}^{2}-m^{2} \\
& m_{\chi}^{2}\left(\phi_{c}\right)=\lambda \phi_{c}^{2}-m^{2}
\end{aligned}
$$

sehingga $m_{h}^{2}(\nu)=2 \lambda v^{2}=2 m^{2}$ dan $m_{\chi}^{2}=0$. Boson tera yang memberikan sumpangan pada potensial loop-tunggal adalah $W^{ \pm}$dan $Z$

$$
\begin{aligned}
m_{W}^{2}\left(\phi_{c}\right) & =\frac{g^{2}}{4} \phi_{c}^{2} \\
m_{Z}^{2}\left(\phi_{c}\right) & =\frac{g^{2}+g^{\prime 2}}{4} \phi_{c}^{2}
\end{aligned}
$$

Sehingga hanya fermion, quark top, yang memberikan kontribusi yang signifikan terhadap potensial efektif loop-tunggal, dengan massa yang bergantung medan

$$
m_{t}^{2}\left(\phi_{c}\right)=\frac{h_{t}^{2}}{2} \phi_{c}^{2}
$$

dengan $h_{t}$ adalah kopling Yukawa untuk top quark.

Potensial efektif loop-tunggal $V_{1}\left(\phi_{c}\right)$ dapat dihitung dengan menggunakan potensial efektif loop-tunggal pada medan skalar, fermion, dan boson tera berikut ini.

Regularisasi cut-off dengan memasukkan nilai minimum pada $v=246.22 \mathrm{GeV}$, dan massa Higgs tidak berubah terhadap nilai tree levelnya,

$$
\begin{gathered}
\left.\frac{d\left(V_{1}+V_{1}^{c . t .}\right)}{d \phi_{c}}\right|_{\phi_{c}=v}=0 \\
\left.\frac{d^{2}\left(V_{1}+V_{1}^{c . t .}\right)}{d \phi_{c}^{2}}\right|_{\phi_{c}=v}=0
\end{gathered}
$$

Sekarang dapat digunakan persamaan (46) untuk menuliskan

$$
\begin{aligned}
V_{1}\left(\phi_{c}\right)=\frac{1}{32 \pi^{2}} & \sum_{i=W, Z, t, h, \chi} n_{i}\left[m_{i}^{2}\left(\phi_{c}\right) \Lambda^{2}\right. \\
& \left.+\frac{m_{i}^{4}\left(\phi_{c}\right)}{2}\left(\log \frac{m_{i}^{2}\left(\phi_{c}\right)}{\Lambda^{2}}-\frac{1}{2}\right)\right]
\end{aligned}
$$


Masukkan kondisi (75) ketakberhinggaan pada (76) dicancel terhadap $V_{1}^{\text {c.t. }}$, dan menghasilkan kebergantungan potensial- $\phi_{c}$ yang berhingga,dan diberikan oleh,

$$
\begin{aligned}
V\left(\phi_{c}\right)=V_{0}\left(\phi_{c}\right)+ & \frac{1}{64 \pi^{2}} \sum_{i}\left\{m_{i}^{4}\left(\phi_{c}\right)\left(\log \frac{m_{i}^{2}\left(\phi_{c}\right)}{m_{i}^{2}(v)}-\frac{3}{2}\right)\right. \\
& \left.+2 m_{i}^{2}(v) m_{i}^{2}\left(\phi_{c}\right)\right\}
\end{aligned}
$$

Suku pasangan $\delta \Omega, \delta m^{2}$ dan $\delta \lambda$ pada (40) diberikan oleh

$$
\begin{aligned}
\delta \lambda= & -\frac{1}{16 \pi^{2}} \sum_{i} n_{i}\left(\frac{m_{i}^{2}(v)-b_{i}}{v^{2}}\right)^{2}\left(\log \frac{m_{i}^{2}(v)}{\Lambda^{2}}+1\right) \\
\delta m^{2}= & -\frac{1}{16 \pi^{2}} \sum_{i} n_{i} \frac{m_{i}^{2}-b_{i}}{v^{2}}\left[\Lambda^{2}-m_{i}^{2}(v)\right. \\
& \left.+b_{i}\left(\log \frac{m_{i}^{2}(v)}{\Lambda^{2}}+1\right)\right] \\
\delta \Omega= & \frac{m^{2}}{32 \pi^{2}} \sum_{i=h, \chi} n_{i}\left[\Lambda^{2}-m_{i}^{2}(v)\right. \\
& \left.+\frac{b_{i}}{2}\left(\log \frac{m_{i}^{2}(v)}{\Lambda^{2}}+1\right)\right]
\end{aligned}
$$

dengan $b_{W}=b_{Z}=b_{t}=0$ and $b_{h}=b_{\chi}=-m^{2}$.

Tampak pada (78) bahwa dengan mengabaikan kontribusi pada potensial efektif loop-tunggal dari sektor Higgs menghasilkan pada hilangnya konstanta kosmologi. $\delta m^{2}$ juga dibangkitkan oleh kontribusi dari boson tera dan loop quark top.

\section{Temperatur Hingga}

Menggunakan persamaan (64) dan (68), bagian temperaturberhingga dari potensial efektif loop-tunggal dapat dituliskan,

$$
\begin{aligned}
\Delta V^{(1)}\left(\phi_{c}, T\right)=\frac{T^{4}}{2 \pi^{2}} & {\left[\sum_{i=W, Z} n_{i} J_{B}\left[m_{i}^{2}\left(\phi_{c}\right) / T^{2}\right]\right.} \\
& \left.+n_{t} J_{F}\left[m_{t}^{2}\left(\phi_{c}\right) / T^{2}\right]\right]
\end{aligned}
$$

dengan fungsi $J_{B}$ dan $J_{F}$ adalah fungsi thermal boson dan fermion secara berurutan.

Menggunakan ekspansi temperatur tinggi dari boson dan fermion, dan potensial efektif loop-tunggal pada temperatur nol, potensial total dapat dituliskan secara keseluruhannya

$$
V\left(\phi_{c}, T\right)=D\left(T^{2}-T_{o}^{2}\right) \phi_{c}^{2}-E T \phi_{c}^{3}+\frac{\lambda(T)}{4} \phi_{c}^{4}
$$

dengan koefisien-koefisiennya adalah

$$
\begin{aligned}
D= & \frac{2 m_{W}^{2}+m_{Z}^{2}+2 m_{t}^{2}}{8 v^{2}} \\
E= & \frac{2 m_{W}^{3}+m_{Z}^{3}}{4 \pi v^{3}} \\
T_{o}^{2}= & \frac{2 v^{2} m_{h}^{2}-3\left(2 m_{W}^{4}+m_{Z}^{4}-4 m_{t}^{4}\right) / 4 \pi^{2}}{2 m_{W}^{2}+m_{Z}^{2}+2 m_{t}^{2}} \\
\lambda(T)= & \lambda-\frac{3}{16 \pi^{2} v^{4}}\left(2 m_{W}^{4} \log \frac{m_{W}^{2}}{A_{B} T^{2}}\right. \\
& \left.+m_{Z}^{4} \log \frac{m_{Z}^{2}}{A_{B} T^{2}}-4 m_{t}^{4} \log \frac{m_{t}^{2}}{A_{F} T^{2}}\right)
\end{aligned}
$$

dengan $\log A_{B}=\log a_{b}-3 / 2 \operatorname{dan} \log A_{F}=\log a_{F}-3 / 2$, dan $a_{B}, a_{F}$ telah diberikan sebelumnya. Semua massa yang tampak pada definisi koefisien-koefisien, persamaan (81), merupakan massa fisis yaitu massa pada temperatur minimum nol.

\section{B. Transisi Fasa}

Pada masa sangat awal evolusinya alam semesta dipenuhi oleh materi pada energi dan kerapatan sangat tinggi. Untuk memahami bagaimana transisi fasa berlangsung kita perlu mengkaji evolusi potensial terhadap temperatur. Potensial efektif loop-tunggal untuk model standar $V(\phi, T)$ diberikan oleh bentuk (80)

$$
V(\phi, T)=D\left(T^{2}-T_{o}^{2}\right) \phi^{2}-E T \phi^{3}+\frac{\lambda(T)}{4} \phi^{4} .
$$

dengan $D$ dan $E$ konstan sedangkan $\lambda$ berevolusi terhadap temperatur secara lamban.

Pada temperatur sangat tinggi rapat energi sistem seperti diberikan oleh potensial (82) tampak hanya mempunyai satu minimum yaitu pada $\phi=0$. Seiring dengan menurunnya temperatur sistem potensial efektif mempunyai minimum ekstra pada nilai medan

$$
\phi=\frac{3 E T}{2 \lambda(T)}
$$

yang muncul sebagai titik belok pada temperatur $T=T_{1}$

$$
T_{1}^{2}=\frac{T_{o}^{2}}{1-9 E^{2} / 8 \lambda\left(T_{1}\right) D}
$$

Temperatur terus menurun dan minimum lokal pada $\phi(T) \neq 0$ mulai terbentuk. Dengan demikian, pada temperatur ini terdapat penghalang antara minimum mutlak pada $\phi=0$ dan minimum lokal

$$
\phi_{m}(T)=\frac{3 E T}{2 \lambda(T)}+\frac{1}{2 \lambda(T)} \sqrt{9 E^{2} T^{2}-8 \lambda(T) D\left(T^{2}-T_{o}^{2}\right)}
$$

dan penghalang mempunyai maksimum pada

$$
\phi_{M}(T)=\frac{3 E T}{2 \lambda(T)}-\frac{1}{2 \lambda(T)} \sqrt{9 E^{2} T^{2}-8 \lambda(T) D\left(T^{2}-T_{o}^{2}\right)}
$$


Ketika temperatur mencapai nilai kritis $T=T_{c}$

$$
T_{c}^{2}=\frac{T_{o}^{2}}{1-E^{2} / \lambda\left(T_{c}\right) D}
$$

potensial minimum terdegenerasi yaitu di $\phi=0$ dan

$$
\phi_{m}\left(T_{c}\right)=\phi_{c}=\frac{2 E T_{c}}{\lambda\left(T_{c}\right)}
$$

Sedangkan puncak penghalang atau maksimum lokal terjadi pada

$$
\phi_{M}\left(T_{c}\right)=\frac{E T_{c}}{\lambda\left(T_{c}\right)} .
$$

Ketika temperatur $T<T_{c}$ minimum pada $\phi=0$ menjadi tidak stabil dan minimum pada $\phi_{m}(T) \neq 0$ menjadi minimum global. Pada $T=T_{o}$ penghalang tidak tampak lagi dan

$$
\phi_{M}\left(T_{o}\right)=0
$$

menjadi maksimum sedangkan

$$
\phi_{m}\left(T_{o}\right)=\frac{3 E T_{o}}{\lambda\left(T_{o}\right)}
$$

menjadi minimum baru. Evolusi potensial efektif terhadap temperatur secara umum diberikan oleh Gambar 4

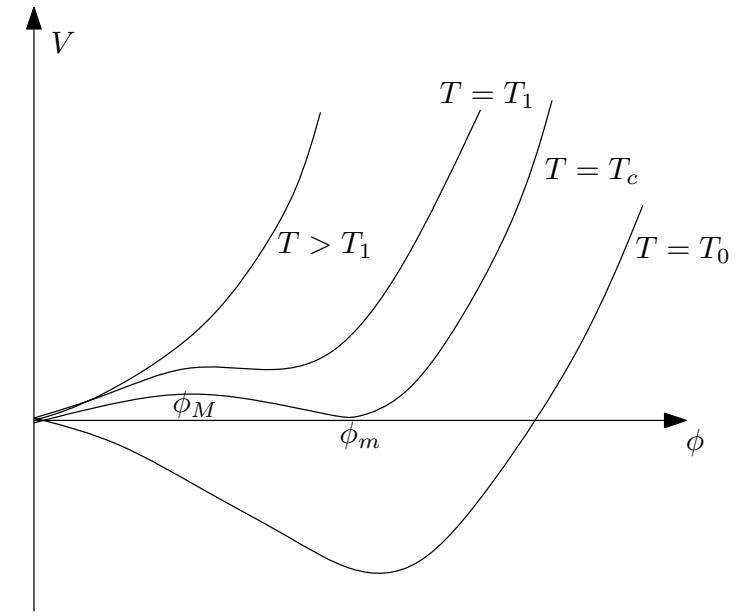

Gambar 4: Evolusi potensial terhadap perubahan temperatur

\section{Ucapan Terima Kasih}

Penulis sampaikan terimakasih kepada Prof. Fredy Permana Zen, DSc dan Dr. rer.nat Bobby Eka Gunara di lab fisika teori ITB atas diskusinya.

\section{SIMPULAN}

Di dalam skenario kosmologi big bang panas, alam semesta bermula dari temperatur yang sangat tinggi dan bergantung pada potensial efektif temperatur berhingga, saat itu alam semesta berada dalam fasa simetrik dan $\phi=0$ berupa minimum stabil absolut. Alam semesta mendingin menuju temperatur kritis $T_{c} \sim 100 \mathrm{GeV}$ ketika simetri antara interaksi lemah dan elektromagnetik rusak minimum pada $\phi=0$ menjadi metastabil dan transisi fasa dapat berlangsung.

Transisi fasa yang berlangsung adalah transisi fasa orde pertama karena terdapat penghalang antara fasa simerti dan fasa rusak. Sebaliknya, jika tidak ada penghalang antara fasa simetrik dan fasa simetri rusak maka transisi fasa adalah orde dua.

Transisi dari vakum "salah" ke vakum sejati terjadi melalui proses penerowongan termal (thermal tunneling). Hal ini dapat dipahami sebagai pembentukan gelembung dari fasa simetri rusak pada lautan fasa simetrik. Ketika hal ini terjadi, gelembung menjalar ke seluruh bagian alam semesta mengkorversi vakum salah ke vakum sejati.

Penyimpangan bilangan baryon anomali di dalam standar model pada temperatur tinggi berlangsung cepat maka keluar dari kesetimbangan pada transisi fasa elektrolemah orde pertama membuka kemungkinan bagi baryogenesis model standar. Selanjutnya perlu dikaji kekuatan dari transisi fasa ini untuk mendapatkan pemahaman kuantitatif seberapa efektif baryogenesis di dalam elektrolemah ini terjadi.

\section{LAMPIRAN A: FREKWENSI MATSUBARA BOSONIK}

Perhatikan integral (54) dan definisikan,

$$
v(\omega)=\sum_{n=-\infty}^{\infty} \log \left(\omega_{n}^{2}+\omega^{2}\right)
$$

dengan $\omega_{n}=2 n \pi \beta=2 n \pi / T$ Turunannya terhadap $\omega$ memberikan,

$$
\frac{\partial v}{\partial \omega}=\sum_{n=-\infty}^{\infty} \frac{2 \omega}{\omega_{n}^{2}+\omega^{2}}
$$

Menggunakan identitas,

$$
\begin{aligned}
f(y)=\sum_{n=1}^{\infty} \frac{y}{y^{2}+n^{2}} & =-\frac{1}{2 y}+\frac{1}{2} \pi \operatorname{coth} \pi y \\
& =-\frac{1}{2 y}+\frac{\pi}{2}+\pi \frac{e^{-2 \pi y}}{1-e^{-2 \pi y}}
\end{aligned}
$$

dengan $y=\beta \omega / 2 \pi$ diperoleh,

$$
\frac{\partial v}{\partial \omega}=2 \beta\left[\frac{1}{2}+\frac{e^{-\beta \omega}}{1-e^{-\beta \omega}}\right]
$$

dan

$$
v(\omega)=2 \beta\left[\frac{w}{2}+\frac{1}{\beta} \log \left(1-e^{-\beta \omega}\right)\right]+\operatorname{bebas} \omega
$$

Suku pertama dapat diuraikan menggunakan identitas,

$$
-\frac{i}{2} \int_{-\infty}^{\infty} \frac{d x}{2 \pi} \log \left(-x^{2}+\omega^{2}-i \epsilon\right)=\frac{\omega}{2}
$$


yaitu

$$
\omega \int_{-\infty}^{\infty} \frac{d x}{2 \pi i} \frac{1}{-x^{2}+\omega^{2}-i \epsilon}=\frac{1}{2}
$$

Integral (A7) dapat dikerjakan pada interval integral tertutup $(-\infty, \infty)$ dalam ruang complex $x$ sepanjang lintasan (kontur) yang bergerak berlawanan dengan arah jarum jam dan meninggalkan kutub pada $x=-\sqrt{\omega^{2}-i \epsilon}$ dengan residu $1 / 2 \omega$. Sekarang gunakan identitas (A6) untuk menuliskan bagian yang tak mengandung temperatur dari (A5) sebagai

$$
\frac{1}{2} \int \frac{d^{3} p}{(2 \pi)^{3}} \omega=-\frac{i}{2} \int \frac{d^{4} p}{(2 \pi)^{4}} \log \left(-p_{o}^{2}+\omega^{2}-i \epsilon\right)
$$

dan, setelah rotasi Wick $p^{0}=i p_{E}$ pada (A8) diperoleh,

$$
\frac{1}{2} \int \frac{d^{3} p}{(2 \pi)^{3}} \omega=\frac{1}{2} \int \frac{d^{4} p}{(2 \pi)^{4}} \log \left[p^{2}+m^{2}\left(\phi_{c}\right)\right] .
$$

\section{LAMPIRAN B: FREKWENSI MATSUBARA FERMIONIK}

Untuk medan fermion, penjumlahan meliputi semua $n$ ganjil dan dimodifikasi terhadap penjumlahan untuk semua $n$ dengan trik yang sama seperti kasus boson. $f(y)$ diberikan (A3), kemudian,

$$
\begin{aligned}
\sum_{m=2,4, \ldots} \frac{y}{y^{2}+m^{2}} & =\sum_{n=1}^{\infty} \frac{y}{y^{2}+4 n^{2}}=\frac{1}{2} f\left(\frac{y}{2}\right) \\
\sum_{m=1,3, \ldots} \frac{y}{y^{2}+m^{2}} & =f(y)-\frac{1}{2} f\left(\frac{y}{2}\right)
\end{aligned}
$$

dan menggunakan (A3) diperoleh,

$$
\sum_{m=1,3, \ldots} \frac{y}{y^{2}+m^{2}}=\frac{\pi}{4}-\frac{\pi}{2} \frac{1}{e^{\pi y}+1}
$$

Fungsi $v(\omega)$ dapat dituliskan sebagai,

$$
v(\omega)=2 \sum_{n=1,3, \ldots} \log \left[\frac{\pi^{2} n^{2}}{\beta^{2}}+\omega^{2}\right]
$$

dan turunannya,

$$
\frac{\partial v}{\partial \omega}=\frac{4 \beta}{\pi} \sum_{1,3, \ldots} \frac{y}{y^{2}+n^{2}}
$$

dengan $y=\beta \omega / \pi$. Kemudian menggunakan (B2) diperoleh

$$
\frac{\partial v}{\partial \omega}=2 \beta\left[\frac{1}{2}-\frac{1}{1+e^{\beta \omega}}\right]
$$

dan, setelah integrasi terhadap $\omega$,

$$
v(\omega)=2 \beta\left[\frac{w}{2}+\frac{1}{\beta} \log \left(1+e^{-\beta \omega}\right)\right]+\text { bebas } \omega
$$

[1] S.L. Glashow, Nucl. Phys. 22, 579 (1961); A.Salam, in Elementary Particle Theory, eds. N.Svartholm, Almqvist and Wiksell (Stockholm, 1968); and S. Weinberg, Phys.Rev.Lett. 19, 1264 (1967).

[2] E.W.Kolb and M.S.Turner, The Early Universe (AddisonWesley, New York, 1990).

[3] A.D. Sakharov, Zh.Eksp.Teor.Fiz. 5, 32 (1967); JETP Lett. 524 (1967).
[4] N. Cabibbo, Phys. Rev. Lett. 10531 (1963); M. Kobayashi and T. Maskawa, Prog. Theor. Phys. 49652 (1973).

[5] T.P.Cheng and L.F.Li, Gauge Theory of Elementary Particle Physics (Oxford University Press, New York, 1984).

[6] A.Das, Finite Temperature Field Theory (World Scientific, Singapore, 1997). 